\title{
Dynamic approaches to demand model in evacuation conditions
}

\author{
F. Russo \& G. Chilà \\ LAST - Laboratory for Transport Systems Analysis, \\ Mediterranea University of Reggio Calabria, Italy
}

\begin{abstract}
Simulation of evacuation demand in some emergency conditions requires the use of dynamic models, among which sequential dynamic discrete choice models represent a special class. Sequential dynamic discrete choice models are based on discrete choice model theory and on sequential analysis, a statistical approach which allows one to analyze the given dynamic phenomenon in the sample database and to highlight, if it exists, a specific lag. This work is subdivided into two main parts. In the first part we propose an analysis of evacuation conditions requiring a dynamic approach and a state of the art of literature models which deal with these. In the second part we propose a brief description of sequential analysis and we introduce a sequential dynamic discrete choice model to simulate evacuation conditions.
\end{abstract}

Keywords: evacuation conditions, sequential dynamic demand model.

\section{Introduction}

Demand models are a fundamental tool for solving most problems in transport systems planning and management. Several mathematical models to simulate transport demand are proposed in the literature. These are based on various assumptions and can be subdivided in relation to different elements: type of choice implicitly or explicitly simulated by the model; approach taken for simulating travel demand, i.e. the reciprocal conditioning of decisions; basic assumptions of the models, which can be behavioural if they derive from explicit assumptions about user choice behaviour, or descriptive otherwise. In most cases, these models belong to discrete choice models, which are defined in 
respect of the: decision maker, choice set, attributes and parameters, random residuals $[1,2]$.

Discrete choice models are usually derived under the assumption of utilitymaximizing behaviour by the decision maker and are applied to simulate several choices of transport and mobility, such as mode choice, path choice and car ownership [2, 3].

When a dangerous event occurs, in evacuation conditions, demand models specified and calibrated in ordinary conditions cannot be directly applied for several reasons: multiplicity of decision-makers; definition of choice set, which may differ for evacuation scenarios and for decision makers; statistical and probabilistic aspects; attributes and parameters [4, 5].

Moreover, in evacuation conditions the analyst must consider possible targets set by the public decision-maker, in order to reduce system management costs, maximise the system utility (safety, security) and reduce traffic incidents [6].

Of course, to simulate an evacuation we need to start from the knowledge of the category of people who will be in the zone and, for each category, what decisions will be taken: to move or not; if so, where to and on what mode. First, as in ordinary conditions, the analyst has to define the study area and develop zoning and socio-economic analysis.

Different demand models have to be specified, in relation to event types, which can be classified in relation to $[4,5,7,8]$ :

event kind, which can be natural or anthropogenic;

- effect in a transport system, which may be on demand, supply or demandsupply interaction;

- effect in space, which can be punctual or diffuse;

- effect in time, which can be immediate or delayed;

In the case in point we focus on the event classification in relation to its effect in the time. In the demand analysis, we consider a delayed or immediate approach, in relation to the time gap available between the time at which the dangerous event will happen is known and the time when the event starts its effects on the population. In relation to the fig. $1[5,6]$, we define:

- $\mathrm{t}_{0}$ initial instant at which we decide to plan [9-11];

- $\mathrm{t}_{1}$ time at which the time when the dangerous event will happen is known or supposed forecasted;

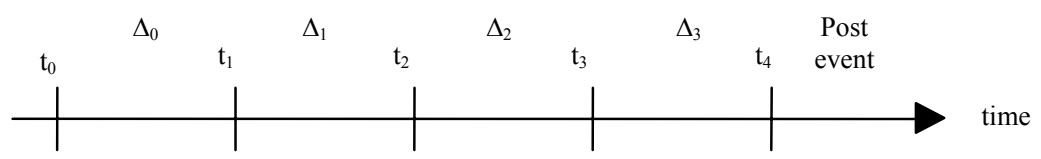

Effects on population

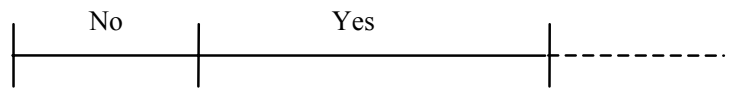

Mitigation actions

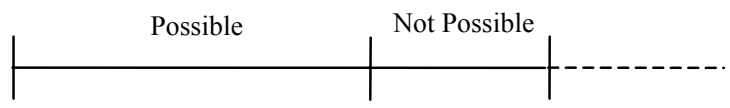

Figure 1: Temporal evolution of a dangerous event. 
- $t_{2}$ time at which the threat occurs and becomes a dangerous event;

- $t_{3}$ time at which the event starts its effects;

- $\mathrm{t}_{4}$ time at which the dangerous event ceases its effects on the population.

If $\Delta_{1}+\Delta_{2}=\left(\mathrm{t}_{3}-\mathrm{t}_{1}\right) \neq 0$ we consider a delayed approach and during this gap there is the possibility to evacuate the population and then reduce the effect when the event occurs. In these cases, such as tsunami, hurricane, some kind of landslide and flash food and so on, population evacuation could be planned and delayed in the time.

In table 1 we propose $\Delta$ intervals for several dangerous event. For the hurricane, for example:

Table 1: $\quad$ Specification of temporal evolution for several kinds of dangerous events.

\begin{tabular}{ccccc}
\hline Example & $\Delta_{0}$ & $\Delta_{1}$ & $\Delta_{2}$ & $\Delta_{3}$ \\
\hline Tsunami & $\neq 0$ & $\neq 0$ & $\neq 0$ & $\approx 0$ \\
Hurricane & $\neq 0$ & $\neq 0$ & $\neq 0$ & $\neq 0$ \\
Twin Towers & $\neq 0$ & $\neq 0$ & $\neq 0$ & $\neq 0$ \\
Bomb & $\neq 0$ & $\neq 0$ & $\approx 0 / \neq 0$ & $\approx 0$ \\
Cistern & $\neq 0$ & $\neq 0$ & $\neq 0$ & $\neq 0$ \\
Chemistry pollution & $\neq 0$ & $\neq 0$ & $\neq 0$ & $\neq 0$ \\
Vulcan eruption & $\neq 0$ & $\approx 0$ & $\neq 0$ & $\neq 0$ \\
Earthquake & $\neq 0$ & 0 & 0 & 0 \\
\hline
\end{tabular}

$\Delta_{0}$, that is the interval between $t_{0}$ and $t_{1}$ time, respectively, at which an hypothetical public decision maker decide to plan an evacuation from a considered area and at which it is possible to know when the hurricane will be in the considered area, isn't null;

- $\Delta_{1}$, that is the interval between $t_{1}$ and $t_{2}$, time at which the hurricane reach the considered area, isn't null;

- $\Delta_{2}$, that is the interval between $t_{2}$ and $t_{3}$, time at which the hurricane starts its effects, isn't null;

- $\Delta_{3}$, that is the interval between $t_{3}$ and $t_{4}$, time at which the hurricane ceases its effects on the population, isn't null.

In the following we propose a state of the art of literature models analyzing demand evacuation for dangerous event with delayed effects in the time, as the conditions in the hurricane case (sec. 2) and a brief description of sequential analysis with the definition of sequential dynamic discrete choice model to simulate evacuation conditions (sec. 3).

\section{Recent literature on models simulating evacuation conditions for dangerous events with delayed effects in the time: the hurricane case}

In the consolidated literature, demand models are simulated considering a multistep approach, including several user decisions: evacuate or not (generation), when (departure-time), towards which destination (distribution), by which 
transport mode (modal choice) and by which path (path choice). In the following, a state of the art on demand models analyzing evacuation conditions for dangerous events with delayed effects in the time is proposed; literature demand models are analyzed in relation to considered user decisions.

A dangerous event with delayed effects in the time which is analyzed in several literature papers is the hurricane. In a large part of these papers, two user decisions are simulated: evacuate or not and when. These decisions are simulated considering a statistical approach, using simple relationships such as means, rates, and distributions [12]. For example, the most common method of estimating evacuation demand is to use evacuation participation rates of evacuation zones. These rates are function of severity of the storm and are based on past observed behaviour [13]. Some researchers report the use of response curve, sensitive to the characteristics of the hurricane, time of day, type and timing of evacuation order, to simulate evacuation demand. These curves have been subjectively established based on past evacuation behaviour and relate the proportion evacuating to the time since issuing an evacuation order [14]. Wilmot and $\mathrm{Fu}$ [13] propose a model estimating a joint decision, generation with departure time, in the face of an oncoming hurricane, as a series of binary choices over time. Models named as sequential binary logit are proposed, simulating the probability of a household evacuating, at each time period before dangerous event. These models are first derived using the random utility principle.

Let $U_{e}^{n, t}$ and $U_{n e}^{n, t}$ be the utility of a household $n$ choosing to evacuate and not to evacuate, respectively, in time interval $t$, provided that the $t$ interval was reached without evacuation. According to the random utility theory, the probability of a household evacuating in time interval $\mathrm{t}, \forall \mathrm{t}^{\prime} \neq \mathrm{t}$, is:

$$
\mathrm{P}^{\mathrm{t}}=\operatorname{Pr}\left(\mathrm{U}_{\mathrm{e}}^{\mathrm{n}, \mathrm{t}} \geq \mathrm{U}_{\text {ne }}^{\mathrm{n}, \mathrm{t}} \mid \mathrm{U}_{\text {ne }}^{\mathrm{n}, \mathrm{t}^{\prime}}>\mathrm{U}_{\mathrm{e}}^{\mathrm{e}, \mathrm{t}^{\prime}}\right)=\operatorname{Pr}\left(\mathrm{U}_{\mathrm{e}}^{\mathrm{n}, \mathrm{t}}-\mathrm{U}_{\text {ne }}^{\mathrm{n}, \mathrm{t}} \geq 0 \mid \mathrm{U}_{\text {ne }}^{\mathrm{n}, \mathrm{t}^{\prime}}-\mathrm{U}_{\mathrm{e}}^{\mathrm{e}, \mathrm{t}^{\prime}}>0\right)
$$

If the utility difference terms $\Delta \mathrm{U}^{\mathrm{t}^{\prime}}=\mathrm{U}_{\mathrm{ne}}^{\mathrm{n}, \mathrm{t}^{\prime}}-\mathrm{U}_{\mathrm{e}}^{\mathrm{n}, \mathrm{t}^{\prime}}$ are independent among all time intervals, then:

$$
\mathrm{P}^{\mathrm{t}}=\operatorname{Pr}\left(\mathrm{U}_{\mathrm{e}}^{\mathrm{n}, \mathrm{t}}-\mathrm{U}_{\mathrm{ne}}^{\mathrm{n}, \mathrm{t}} \geq 0\right) \prod_{\mathrm{t}^{\prime}=1}^{\mathrm{t}-1}\left[1-\operatorname{Pr}\left(\mathrm{U}_{\mathrm{e}}^{\mathrm{n}, \mathrm{t}^{\prime}}-\mathrm{U}_{\mathrm{ne}}^{\mathrm{n}, \mathrm{t}^{\prime}} \geq 0\right)\right],
$$

where $\left[1-\operatorname{Pr}\left(\mathrm{U}_{\mathrm{e}}^{\mathrm{n}, \mathrm{t}^{\prime}}-\mathrm{U}_{\text {ne }}^{\mathrm{n}, \mathrm{t}^{\prime}} \geq 0\right)\right], \mathrm{t}^{\prime}=1,2, \ldots \mathrm{t}$, is the conditional probabilities of a household to evacuate in time interval t' respectively, provided that the household has not evacuated yet.

In relation to destination choice simulation, a disaggregate choice model for hurricane evacuation was developed with post hurricane Floyd survey data collected in South Carolina in 1999. A multinomial logit model was used to investigate the effect of risk areas in the path, or projected path, of a hurricane, and destination socioeconomic and demographic characteristics on destination 
choice behaviour. Models were developed for persons evacuating to friends or relatives, or hotels or motels separately [15].

A model including as sub-model generation, distribution and modal choice is proposed in Russo and Chilà [5]. The generation sub-model gives the level of demand in the study area according to the reference period and the population category; the modal split sub-model gives the number of people using a given transport mode from a certain origin to a certain refuge area; the distribution submodel gives the number of people choosing a given refuge area. Each submodel is specified for different user categories. In the paper, moreover, a joint sub-model, simulating modal choice with distribution, is proposed. Each submodel is estimated using data obtained from real experimentation in the urban area of Melito Porto Salvo (Italy) in relation to the research project SICURO [16]. The simulated scenario concerns, as dangerous event with delayed effect in the time, an incident involving a tank transporting dangerous goods which on a workday morning is learning.

It is important to highlight that in the literature on hurricanes, there exist large data collections which allow demand model estimation by means of RP (revealed preference) surveys. RP surveys include preferences inferred from observations of a decision maker's actual choices, in relation to real contexts. However, since RP data are not available for all dangerous events, models specified for hurricane evacuation, which are derived from observation of past evacuation behaviour, cannot be directly applied to other dangerous events. Demand model estimation becomes a complex problem, particularly when unpredictable events happen and users fail to respect targets set by the public decision maker. Prediction of user behaviour becomes essential. For this purpose, evacuation trials and SP (stated preference) surveys may be conducted [17]. Such surveys represent the stated behaviour of users in relation to hypothetical contexts. During evacuation trials, RP data can be obtained, even if they are affected by the laboratory effect, because each user participating in evacuation trials knows that he/she runs no real danger. SP surveys should be considered as complementary to traditional RP surveys and the combined use of the two can balance reciprocal merits and shortcomings.

In light of such considerations, SP surveys play a very important role and RP surveys during evacuation trials may be viewed as physical checking SP data.

Advancements in the specification and calibration of a model simulating transport demand in evacuation conditions are proposed in Russo and Chilà [18, 19], related to the research project SICURO.

In relation to this research project, more users' decisions have been analyzed. A model simulating path choice for emergency vehicle is proposed by Vitetta et al. [20-22]. In this paper, the definition of procedures to be planned and activated in emergencies in order to allow the evacuation of less able users and the design of the optimal path for emergency vehicles are proposed.

Finally, the interaction of demand and supply in emergency conditions is analyzed in Vitetta et al. [23-25]. 


\section{The sequential dynamic discrete choice model}

In this work we recall the model classification proposed in literature [26] and we define a model as:

- non-dynamic (ND), if they give the choice probability without considering system evolution;

- dynamic (D), if they give the choice probability while considering system evolution.

Under the assumption of random utility models (RUM) let be:

- $\quad t$ the generic current time interval;

- $\mathrm{t}-1$ the generic previous time interval;

- $\mathrm{n}$ the generic user class;

- $\mathrm{j}^{\mathrm{t}}$ the chosen alternative in time $\mathrm{t}$;

- $\mathrm{i}^{\mathrm{t}}$ the generic alternative in time $\mathrm{t}$;

- $\mathrm{k}^{\mathrm{t}-1}$ the chosen alternative in time $\mathrm{t}-1$;

- $\mathrm{r}^{\mathrm{t}-1}$ the generic alternative in time $\mathrm{t}-1$; with $\mathrm{j}^{\mathrm{t}}, \mathrm{i}^{\mathrm{t}} \in \mathrm{C}^{\mathrm{t}} ; \mathrm{k}^{\mathrm{t}-1}, \mathrm{r}^{\mathrm{t}-1} \in \mathrm{C}^{\mathrm{t}-1}$.

In the evolution of the system various cases can happen. In general, we have an evolution of user characteristics or level of service as perceived by the reference user. If we use $\mathrm{X}$ to indicate such attributes, we have $\mathrm{X}^{\mathrm{t}-1} \neq \mathrm{X}^{\mathrm{t}}$. Another evolution can be in user taste, hence in user evaluation of attributes. If this is represented by $\beta$, then $\beta^{\mathrm{t}-1} \neq \beta^{\mathrm{t}}$. Finally, we can have $\mathrm{C}^{\mathrm{t}-1} \neq \mathrm{C}^{\mathrm{t}}$, but in this case an evident discontinuity is introduced in the system, since a new choice alternative arises from t- 1 to $t$; this case is the opposite of the sequential case, and cannot be represented as a sequence, just because the process has no linear history, but from a general view it can be considered a bifurcation point.

Given that $\mathrm{C}^{\mathrm{t}-1}=\mathrm{C}^{\mathrm{t}} \equiv \mathrm{C}$, we assume that the choice set is fixed and then we can write, without loss of generality, $\mathrm{k}^{\mathrm{t}-1}=\mathrm{j}^{\mathrm{t}-1}$ and $\mathrm{r}^{\mathrm{t}-1}=\mathrm{i}^{\mathrm{t}-1}$, using for the same alternative the same representative variable in $\mathrm{t}$ and in $\mathrm{t}-1$.

Formally we can define as a dynamic model the model that gives the probability that user $n$ chooses the generic alternative $j^{t}$ in $t$, if $\beta^{t-1} \neq \beta^{t}$ and/or $\mathrm{X}^{\mathrm{t}-1} \neq \mathrm{X}^{\mathrm{t}}$, as:

$$
\begin{aligned}
& P^{n, t}\left[j^{t}\right]=\operatorname{prob}\left(U^{n, t}\left[j^{t}\right]>U^{n, t}\left[i^{t}\right] \forall j^{t}, i^{t} \in C, j^{t} \neq i^{t}\right) \\
& \text { with } \mathrm{P}^{\mathrm{n}, \mathrm{t}}\left[\mathrm{j}^{\mathrm{t}}\right] \neq \mathrm{P}^{\mathrm{n}, \mathrm{t}-1}\left[\mathrm{j}^{\mathrm{t}-1}\right] \forall \mathrm{j}^{\mathrm{t}}, \mathrm{j}^{\mathrm{t}-1} \in \mathrm{C}, \mathrm{j}^{\mathrm{t} \neq \mathrm{j}^{\mathrm{t}-1}} \\
& \mathrm{P}^{\mathrm{n}, \mathrm{t}-1}\left[\mathrm{j}^{\mathrm{t}-1}\right]=\operatorname{prob}\left(\mathrm{U}^{\mathrm{n}, \mathrm{t}-1}\left[\mathrm{j}^{\mathrm{t}-1}\right]>\mathrm{U}^{\mathrm{n}, \mathrm{t}-1}\left[\mathrm{i}^{\mathrm{t}-1}\right] \forall \mathrm{j}^{\mathrm{t}-1}, \mathrm{i}^{\mathrm{t}-1} \in \mathrm{C}, \mathrm{j}^{\mathrm{t}-1} \neq \mathrm{i}^{\mathrm{t}-1}\right)
\end{aligned}
$$

In the literature, several specifications of dynamic models are proposed, as regards attributes, parameters or random residuals. Generally, literature models introduce dynamic evolutions of several phenomenons, but they aren't characterized by a statistical structure which allows to analyze the given dynamic phenomenon in the sample database and to highlight, if it exists, a specific lag. In the literature that deals with data analysis, a structure which allows to carry out dynamic analysis of phenomenon is represented by the sequential analysis. 
Sequential analysis arose as science applied itself to observing social behaviour in psychology. Sequential analysis aims to demonstrate how to record observation data, related to user behaviour, in a way that preserves sequential information, and also how to analyze such data in a way that makes use of its sequential nature $[27,28]$. The main question to be analyzed concerns whether or not specific transition frequencies from an antecedent to a consequent state differ from what would be expected if the two states were independent.

In sequential analysis, data related to user behaviour are recorded and analyzed, preserving sequential information and considering a statistical approach. Sequential analysis requires that data be collected in a systematic way. The analyst must set the recording unit, which can be an interval or an event. Depending on how data were recorded, the analyst can extract different representations from the same recorded data for different purposes. Synthetically, there are at least four representation forms, termed the Sequential Data Interchange Standard: event sequences, state sequences, timed-event sequences, interval sequences.

In the following we refer to interval sequences, which is designed to accommodate interval recording in a simple and straightforward way: alternatives are simply listed as they occur and interval boundaries are represented by commas.

Data collected sequentially are summarized using a transition frequency matrix and a second matrix so-called transition probability matrix [26, 29]. The transition frequency matrix is a square matrix which has the same number of rows and columns as events; its generic element $\mathrm{y}_{\mathrm{hw}}$ represents the transition frequency from $\mathrm{h}$ to $\mathrm{w}[26,29]$. These frequencies can also be converted by dividing each $\mathrm{y}_{\mathrm{hw}}$ by the row total for row $\mathrm{h}$. The results can be arranged in a matrix called in literature transition probability matrix (even if aren't present probability as currently defined). The rows of this matrix sum to one.

The reduction of uncertainty by knowledge of past events is the basic concept in sequential analysis. In order to test the significance of this reduction of uncertainty, several tests should be experimented to recorded data [27, 28]. Among these: significance test, stationarity and homogeneity test [29].

Transition matrices are able to represent the choice set for a set of users who have made the same given choice in the previous period. In our work, the data are arranged into a transition matrix and are represented as sequences or chains of alternatives (or behavioural states). Each row of the transition matrix indicates the number of times a particular transition occurred for a sample of decision makers who took a given choice in the previous period. In the present period, the choice set is defined as maintenance or change of the choice set defined in the previous period. For each row of the transition matrix a sequential dynamic discrete choice model could be proposed. The model gives the probability of a user choosing the generic alternative in the current period $t$, conditional upon the probability of the user choosing a given alternative in the previous period $t-1$.

The introduced probability, to be termed a transition probability, could be classified as a special kind of conditional probability. Conditional probabilities are defined as probabilities with which a particular target event occurs, relative 
to another given event. Transition probabilities are distinguished from other conditional probabilities in that the target and given events occur at different and subsequent times.

Considering properties of discrete choice models, properties of sequential analysis and choice alternatives related to the previous periods, sequential dynamic discrete choice model can be defined. This model represent a special class of dynamic discrete choice model, giving the choice probability according to the current and previous system condition, thus considering system evolution and earlier decisions.

Formally, a sequential dynamic discrete choice model is a dynamic model that gives the probability of user $n$ choosing the generic alternative $j^{t}$ in $t, j^{t} \in C^{t}$, conditional upon the probability that user $\mathrm{n}$ has chosen the generic alternative $\mathrm{j}^{\mathrm{t}-1}$ in the previous period $\mathrm{t}-1, \mathrm{j}^{\mathrm{t}-1} \in \mathrm{C}^{\mathrm{t}-1}$, as in the following relation:

$$
\begin{aligned}
& \mathrm{P}^{\mathrm{n}, \mathrm{t}}\left[\mathrm{j}^{\mathrm{t}} / \mathrm{j}^{\mathrm{t}-1}\right]=\operatorname{prob}\left(\mathrm{U}^{\mathrm{n}, \mathrm{t}}\left[\mathrm{j}^{\mathrm{t}}\right]>\mathrm{U}^{\mathrm{n}, \mathrm{t}}\left[\mathrm{i}^{\mathrm{t}}\right] \forall \mathrm{j}^{\mathrm{t}}, \mathrm{i}^{\mathrm{t}} \in \mathrm{C}, \mathrm{j}^{\mathrm{t}} \neq \mathrm{i}^{\mathrm{t}}\right) / \\
& \operatorname{prob}\left(\mathrm{U}^{\mathrm{n}, \mathrm{t}-1}\left[\mathrm{j}^{\mathrm{t}-1}\right]>\mathrm{U}^{\mathrm{n}, \mathrm{t}-1}\left[\mathrm{i}^{\mathrm{t}-1}\right] \forall \mathrm{j}^{\mathrm{t}-1}, \mathrm{i}^{\mathrm{t}-1} \in \mathrm{C}, \mathrm{j}^{\mathrm{t}-1} \neq \mathrm{i}^{\mathrm{t}-1}\right)
\end{aligned}
$$

assuming that:

a physical alternative can change one or more attributes and/or parameters from $\mathrm{t}-1$ to $\mathrm{t}$, without modifying her intrinsic nature; in this way $\mathrm{j}^{\mathrm{t}}$ may or may not be equal to $\mathrm{j}^{\mathrm{t}-1}$, with $\mathrm{j}^{\mathrm{t}}, \mathrm{j}^{\mathrm{t}-1} \in \mathrm{C}^{\mathrm{t}}=\mathrm{C}^{\mathrm{t}-1} \equiv \mathrm{C}$;

$\mathrm{C}^{\mathrm{t}}$ is equal to $\mathrm{C}^{\mathrm{t}-1}$ if both have the same physical alternatives, even if one or more alternatives change one or more attributes or parameters from t- 1 to $t$.

The probability, in this way defined (see eq. (6)), is termed a transition probability and is a kind of conditional probability.

In the same way we can obtain the probability of user $n$ choosing the generic alternative $z^{t} \neq \mathrm{j}^{\mathrm{t}}, \mathrm{z}^{\mathrm{t}} \in \mathrm{C}^{\mathrm{t}}$, conditional upon the probability that user $\mathrm{n}$ has chosen the generic alternative $\mathrm{j}^{\mathrm{t}-1}$ in the previous period $\mathrm{t}-1, \mathrm{z}^{\mathrm{t}-1} \in \mathrm{C}^{\mathrm{t}-1}$.

The sequential dynamic discrete choice model proposed in this section could be specified to simulate user decision, in evacuation conditions, described in section 2. This specification is a work in progress and the relative calibration in a real context is developing using data obtained in the SICURO research project.

\section{References}

[1] Domencich T.A. \& McFadden D. Urban travel demand: a behavioural analysis, American Elsevier, New York, 1975.

[2] Ben Akiva M. \& Lerman S., Discrete choice analysis: theory and application to travel demand, MIT Press, Cambridge, MA, 1985.

[3] Train, K. Discrete choice methods with simulation, MIT Press, Cambridge, MA, 2003.

[4] Russo F. \& Chilà, G., Domanda di trasporto in condizioni di emergenza. Modelli e metodi per la simulazione, applicazione ad un caso reale, Franco Angeli, Milan, 2007.

[5] Russo F. \& Chilà G., Safety of users in road evacuation: demand models. Proc. of Urban Transport XIII, Urban Transport and the Environment in 
the 21st century, Brebbia C. A. (ed.), WIT Press, Southampton, pp. 773782, and in Urban Transport: Safety of Users in Road Evacuation, Russo F. (ed.), WIT Press, Southampton, pp. 11-20, 2007.

[6] Russo, F. \& Vitetta A., Risk evaluation in a transportation system. International Journal of Sustainable Development and Planning, 1 (2), pp. 170-191, 2006.

[7] Russo F. \& Vitetta A., The road network design problem to improve the safety during exogenous flow perturbations. Proc. of the $29^{\text {th }}$ ISATA Conference, Florence, 1996.

[8] Russo F. \& A. Vitetta, Risk in anthropic environments: methodologies for risk evaluation and exposition reduction. Environmental Health Risk III, Brebbia et al., WIT Press, Boston, 2005.

[9] Russo F. \& Rindone C., Safety of users in road evacuation: planning internal processes and guidelines. Proc. of Urban Transport XIII, Urban Transport and the Environment in the 21st century, Brebbia C. A. (ed.), WIT Press, Southampton, pp. 825-834, 2007

[10] Russo F. \& Rindone C., Safety of users in road evacuation: the logical framework approach in evacuation planning. Proc. of Urban Transport $X I V$, Urban Transport and the Environment in the 21st century, Brebbia C. A. (ed.), WIT Press, Southampton, pp. 751-760, 2008.

[11] Russo F. \& Rindone C., Safety of users in road evacuation: Modelling and DSS for LFA in the planning process. Proc. of Sustainable Development and Planning IV, vol.1, Brebbia C. A. (ed.), WIT Press, Southampton, pp. 453-464, 2009.

[12] Wilmot C.G. \& Fu H., Static vs. Dynamic and Aggregate vs. Disaggregate: A Comparison Between Practice and Research in Hurricane Evacuation Travel Demand Modeling. Transp. Research Board 86th Annual Meeting, 2007.

[13] Wilmot C.G. \& Fu H., A sequential logit dynamic travel demand model for hurricane evacuation. Transp. Research Record, 1882, pp.19-26, 2004.

[14] Wilmot, C.G., H. Fu, \&H. Zhang. Modeling the Hurricane Evacuation Response Curve. Transportation Research Record: Journal of Transportation Research Record Board, 2022, pp 94-102, 2007.

[15] Cheng, G., Wilmot C.G. \& R.J. Baker. A destination choice model for hurricane evacuation. Transp. Research Board Annual Meeting, 2008.

[16] Russo F. \& Vitetta A., Safety of users in road evacuation: General methodology and main results. Proc. of Urban Transport XIII, Urban Transport and the Environment in the 21st century, Brebbia C. A. (ed.), WIT Press, Southampton, pp. 763-772, 2007.

[17] Ortuzar, J. \& de D. Willumsen, L.G., Modelling Transport, John Wiley \& Sons Ltd, Chichester, 2006.

[18] Russo F. \& Chilà G., Safety of users in road evacuation: RP vs. SP surveys in demand analysis. Proc. of Urban Transport XIV, Urban Transport and the Environment in the 21 st century, Brebbia C. A. (ed.), WIT Press, Southampton, pp. 703-713, 2008. 
[19] Russo F. \& Chilà G., Safety of users in road evacuation: Modelling and DSS for demand. Proc. of Sustainable Development and Planning IV, vol.1, Brebbia C. A. (ed.), WIT Press, Southampton, pp. 465-474, 2009.

[20] Vitetta A., Quattrone A. \& Polimeni A., Safety of users in road evacuation: design of path choice models for emergency vehicles. Proc. of Urban Transport XIII, Urban Transport and the Environment in the 21st century, Brebbia C. A. (ed.), WIT Press, Southampton, pp. 803-812, 2007.

[21] Vitetta A., Quattrone A. \& Polimeni A., Safety of users in road evacuation: algorithms for path design of emergency vehicles, Proc. of Urban Transport XIV, Urban Transport and the Environment in the 21st century, Brebbia C. A. (ed.), WIT Press, Southampton, pp. 727-737, 2008.

[22] Vitetta A., Quattrone A. \& Polimeni A., Safety of users in road evacuation: Modelling and DSS for paths design of emergency vehicles. Proc. of Sustainable Development and Planning IV, vol.1, Brebbia C. A. (ed.), WIT Press, Southampton, pp. 485-495, 2009.

[23] Vitetta A., Musolino G. \& Marcianò F.A., Safety of users in road evacuation: Supply and demand-supply interaction models for users. Proc. of Urban Transport XIII, Urban Transport and the Environment in the 21st century, Brebbia C. A. (ed.), WIT Press, Southampton, pp. 783-792, 2007.

[24] Vitetta A., Musolino G. \& Marcianò F. A., Safety of users in road evacuation: calibration of cost functions and simulation. Proc. of Urban Transport XIV, Urban Transport and the Environment in the 21st century, Brebbia C. A. (ed.), WIT Press, Southampton, pp. 715-725, 2008.

[25] Vitetta A., Musolino G. \& Marcianò F.A., Safety of users in road evacuation: Modelling and DSS for transport supply and supply-demand interaction. Proc. of Sustainable Development and Planning IV, vol.1, Brebbia C. A. (ed.), WIT Press, Southampton, pp. 475-484, 2009.

[26] Russo F. \& Chilà G., Probit Sequential Model for User's Choices. Proc. of European Transport Conference 2008, Noordwiikerhout (NL), 2008.

[27] Gottman, J.M. \& Roy, K.A., Sequential Analysis, Cambridge University Press, New York, 1990.

[28] Bakeman, R. \& Gottman, J.M., Observing interaction. An introduction to sequential analysis, Cambridge University Press, New York, 1997.

[29] Russo F. \& Chilà G., Sequential models for mobility decisions: experimentation for vehicle holding choices. Proc. of the European Transport Conference 2007, Leeuwenhorst, The Netherlands, 17-19 October 2007.

[30] G. Chilà, Sequential methods for user choices: tests and properties applied to a panel database. Proc. of Urban Transport XIV, Urban Transport and the Environment in the 21 st century, Brebbia C. A. (ed.), WIT Press, Southampton, pp. 121-131, 2008. 